\title{
Is it reasonable to abandon obligatory vaccinations in Italy? A 2013 survey
}

C P Pelullo ${ }^{1}$, S Marino ${ }^{1}$, A J Valdes Abuadili ${ }^{1}$, G Signoriello², F Attena (francesco.attena@unina2.it) ${ }^{3}$

1. School of Hygiene and Preventive Medicine of the Second University of Naples, Naples, Italy

2. Medical Statistics Unit of the Second University of Naples, Naples, Italy

3. Department of Experimental Medicine of the Second University of Naples, Naples, Italy

Citation style for this article:

Pelullo CP, Marino S, Valdes Abuadili AJ, Signoriello G, Attena F. Is it reasonable to abandon obligatory vaccinations in Italy? A 2013 survey. Euro Surveill. 2014;19(35): pii=20889. Available online: http://www.eurosurveillance.org/ViewArticle.aspx?Articleld=20889

Article submitted on 30 January 2014 / published on 04 September 2014

In Italy, infant vaccinations are mandatory for four infectious diseases: diphtheria, polio, tetanus and hepatitis $B$. In the past, there was widespread apprehension in Italy that doing away with obligatory vaccinations would reduce the coverage rate, but the possibility of making vaccinations optional has recently become more popular. The objectives of this study were to investigate parental willingness to vaccinate their children if those vaccinations were no longer mandatory and to evaluate the variables influencing this intention. We conducted face-to-face structured interviews with 1,039 parents at public health vaccination centres in four cities of the Campania region of southern Italy. Most respondents (91.9\%) said that they would certainly $(69.4 \%)$ or probably $(22.5 \%)$ vaccinate their children if vaccinations were not mandatory. The belief that vaccinations are effective and safe was positively associated with willingness to vaccinate their children, whereas having heard that autism is a possible adverse reaction to vaccination was inversely associated with willingness to vaccinate. Nevertheless, in the context of the relatively low 2012* vaccination coverage rates in Campania (under the national standard of $95 \%$ ), our results suggest that eliminating mandatory vaccinations is likely to lead to current coverage rates decreasing to unacceptably low levels, significantly below $90 \%$.

\section{Introduction}

In European countries, childhood immunisation is provided in many different ways. There are large differences in whether vaccinations included in the national programmes are recommended or mandatory. At the end of 2010, among the 27 member countries of the European Union, 13 had no obligatory vaccinations, and 14 had at least one vaccination that was mandatory. For example, vaccination against polio is mandatory for children and adults in 12 countries, diphtheria and tetanus vaccination in 11 countries, and hepatitis $B$ vaccination in 10 countries [1].
In Italy, diphtheria [2], polio [3], tetanus [4] and hepatitis $B$ [5] vaccinations are mandatory. Vaccinations against measles-mumps-rubella (MMR), pertussis, Haemophilus influenzae type $\mathrm{B}$, invasive pneumococcal disease, and Neisseria meningitidis group $\mathrm{C}$ are recommended by the current national vaccination schedule and are offered free of charge. In recent years, health authorities, as national policy, have urged vaccination centres to apply the above four vaccines in the form of a hexavalent vaccine that also includes pertussis and Haemophilus influenzae type B for infant immunisations. Therefore, the hexavalent vaccine is offered as an alternative to the four mandatory vaccines. So, from a practical point of view, pertussis and Haemophilus influenzae type $\mathrm{B}$ vaccines are given as if they are mandatory. Furthermore, in Italy there are significant legislative differences, not only between regions but also over time, due to the strong contrast between attitudes favourable and opposed to the mandatory vaccination. Therefore, there is now less distinction between mandatory and recommended vaccinations than in the past, and the concept of 'mandatory' has become ambiguous. For many years, children were not allowed to attend school if they were not vaccinated [6], but this regulation has been abolished [7], and in recent years, all regions have complied with this abolition. Administrative sanctions for failing to vaccinate a child are rarely applied. If a parent refuses to vaccinate their child, the parent will be called to an informative conversation at the local health authority in an attempt to gain compliance. Legislatively, each Italian region is relatively autonomous, so the laws regarding vaccination vary throughout the country. For example, in the Veneto region, vaccinations are not legally compulsory. After the suspension of obligatory vaccinations, this region has maintained high vaccination coverage. The Veneto region, making all vaccinations non-compulsory, appealed to the sense of responsibility of parents, who no longer had to feel 'forced' and could instead make decisions about vaccinations in a 'conscious' manner [8]. In considering a broader suspension of obligatory vaccinations, it is also important 
to understand which variables influence parental decisions about whether to immunise their children [9-16].

The objectives of this study were (i) to investigate parental willingness to vaccinate their children if vaccinations were no longer mandatory and (ii) to evaluate the variables that influence this intention. We conducted the study in an area of southern Italy with sociocultural characteristics different from the Veneto region of northern Italy.

\section{Methods}

\section{Participants and setting}

In the Campania region of southern Italy, decisions about vaccine types, purchasing, and supply management are centralised at the local health authority and at the regional level. Childhood immunisations are provided at specialised public health vaccination centres (Unità Operative Materno-infantili).

We selected one vaccination centre from each of the four cities with the largest populations in the Campania region (Naples, Salerno, Caserta and Avellino). In Naples, we randomly selected one of the ten vaccination centres. Salerno, Caserta and Avellino each have only one centre. At each centre, two expert healthcare workers interviewed one parent of each child brought for the first, second or third dose of the hexavalent vaccine. When both parents were present at the centre, the workers interviewed only the mother. Written informed consent was obtained from each participant. Interviews were conducted immediately following the vaccinations on one or two days each week between January and April 2013, during all hours that the centres were open to the public.

\section{Sample size}

The target sample size of approximately 1,000 subjects was obtained by assuming a $95 \%$ prevalence of the main outcome, a precision of $\pm 1.2 \%$, a $95 \%$ confidence level and a power of $80 \%$. A total of 1,039 questionnaires were completed (329 in Naples, 254 in Avellino, 251 in Salerno and 205 in Caserta). Using univariate analysis and chi-square tests, we analysed the parents' responses by demographic characteristics and location of vaccination centre. A value of p<0.05 was considered statistically significant.

\section{Questionnaire}

A questionnaire was developed, pilot tested in a full day of interviews in the Naples centre, and consequently modified. The aim was to investigate parents' vaccination intentions, the main outcome variable, by asking, 'Would you immunise your child if vaccinations were not mandatory?' Parents' intentions were scored on a five-point Likert scale, with values of 'certainly', 'probably', 'I don't know', 'probably not' and 'certainly not'. The $95 \%$ confidence interval $(\mathrm{Cl})$ for proportions was calculated for this outcome. In the analysis, the responses were dichotomised by distinguishing those answering 'certainly' and 'probably' from those giving any other response.

The parents were then invited to give their level of agreement with the following statements: 'I am favourable toward vaccination', 'Vaccinations are effective in reducing the risk of disease' and 'Vaccinations are safe' on a five-point Likert scale. The response categories were 'strongly agree', 'somewhat agree', 'I don't know', 'somewhat disagree' and 'strongly disagree'. For analysis, the responses were dichotomised to distinguish agreement ('strongly agree' and 'somewhat agree') from disagreement (all other response categories). Respondents were also asked to express their views on whether vaccinations should be mandatory or optional (response categories of 'entirely mandatory' and 'entirely optional') and on whether vaccinations can cause adverse reactions (response categories of 'never', 'rarely', 'frequently' and always were dichotomised as 'never'/'rarely' vs 'frequently'/'always').

The source of information on the possible adverse effects of vaccination was operationalised by asking, 'In which way have you been informed about the possible adverse reactions after vaccination?' Responses were dichotomised as physician vs other sources. Respondents were also asked whether any of their children had experienced adverse reactions after vaccination. Finally, two questions were asked concerning knowledge about the debate on autism as an adverse reaction and vaccines containing mercury. These questions were placed at the end of questionnaire to avoid influencing the responses to other items. First, respondents were asked, 'Have you ever heard of possible adverse reactions or diseases associated with the administration of vaccines containing mercury?' The second question was modified as a result of the pilot test. Initially, the question was, 'Have you ever heard of autism as a possible adverse reaction after the administration of vaccines?' As some parents were alarmed by this question, it was modified in the final questionnaire: 'Although this hypothesis was disproved, have you ever heard of autism as a possible adverse reaction after the administration of vaccines?'

Sociodemographic data were collected for each respondent: age, education level, marital status, occupation and number of children.

\section{Statistical analysis}

Bivariate tests were used to assess the univariate associations between each of the independent variables and the main outcome. Only those variables associated with the outcome at the $p \leq 0.25$ level in the bivariate analysis were subsequently included in the multivariate regression model. Logistic regression models were then estimated to evaluate the association between the independent variables and the main outcome. Backward stepwise procedures were applied, and the final model included only variables contributing significantly to the explanation of the outcome. Variables 
were selected for the multivariate model using $p<0.2$ for entry and p<0.4 for exclusion. Analyses were carried out using Stata 10 [17].

The final logistic model predicted parents' vaccination intentions 'Would you immunise your child if vaccination was not mandatory?' (no=0; yes $=1$ ). Based on the results of the univariate analysis, independent variables measuring attitudes towards vaccination and knowledge of potential adverse reactions following vaccination were included in the model. Specifically, the included independent variables were: being favourable toward vaccination ( $(n 0=0$, yes $=1$ ); believing that vaccinations are effective (no $=0$, yes $=1$ ); believing that vaccinations are safe $(n o=0$, yes $=1)$; believing that vaccinations should be mandatory (entirely optional $=0$, entirely mandatory $=1$ ); believing that vaccinations can cause adverse reactions $(n o=0$, yes $=1)$; source of information about possible adverse reactions after vaccination (physician $=0$, others $=1$ ); children's previous experience with adverse reactions after vaccination (no $=0$, yes $=1$ ); having heard of possible adverse reactions or diseases associated with the administration of vaccines containing mercury (no $=0$, yes $=1$ ) and having heard of autism as a possible adverse reaction after the administration of vaccines $(n o=0$, yes $=1)$.

\section{TABLE 1}

Selected characteristics of the study population, Italy, 2013 $(\mathrm{n}=1,039)$

\begin{tabular}{|l|c|c|c|c|}
\hline \multirow{2}{*}{ Characteristic } & \multicolumn{2}{|c}{ Mother } & \multicolumn{2}{c|}{ Father } \\
\cline { 2 - 5 } & $\mathrm{n}$ & $\%$ & $\mathrm{n}$ & $\%$ \\
\hline Ag-19 (years) & 927 & 100 & 109 & 100 \\
\hline 20-29 & 12 & 1.3 & 0 & 0 \\
\hline 30-39 & 229 & 24.7 & 15 & 13.8 \\
\hline 40-49 & 516 & 55.7 & 50 & 45.9 \\
\hline 50-59 & 165 & 17.8 & 39 & 35.8 \\
\hline Marital status & 925 & 100 & 108 & 100 \\
\hline Married & 807 & 87.2 & 101 & 93.5 \\
\hline Other & 118 & 12.8 & 7 & 6.5 \\
\hline Education & 927 & 100 & 109 & 100 \\
\hline Primary school & 30 & 3.2 & 2 & 1.8 \\
\hline Middle school & 215 & 23.2 & 18 & 16.5 \\
\hline High school & 370 & 39.9 & 38 & 34.9 \\
\hline College degree & 312 & 33.7 & 51 & 46.8 \\
\hline Occupation & 926 & 100 & 108 & 100 \\
\hline Employed & 465 & 50.2 & 100 & 92.6 \\
\hline Unemployed & 461 & 49.8 & 8 & 7.4 \\
\hline Other children & 926 & 100 & 109 & 100 \\
\hline Yes & 492 & 53.1 & 60 & 55 \\
\hline No & 434 & 46.9 & 49 & 45 \\
\hline Totala & 930 & 89.5 & 109 & 10.5 \\
\hline
\end{tabular}

a Numbers for each item may not sum to the total study population because of missing values.
TABLE 2

Parents' intentions to vaccinate their children, Italy, 2013 $(n=1,039)$

\begin{tabular}{|l|c|c|c|}
\hline $\begin{array}{l}\text { Would you immunise your } \\
\text { child if vaccination were } \\
\text { not mandatory? }\end{array}$ & $\mathrm{n}$ & $\%$ & $95 \% \mathrm{Cl}$ \\
\hline Certainly & 721 & 69.4 & $66.6-72.2$ \\
\hline Probably & 234 & 22.5 & $20.0-25.1$ \\
\hline Probably not & 35 & 3.4 & $2.2-4.4$ \\
\hline Certainly not & 30 & 2.9 & $1.8-3.9$ \\
\hline I don't know & 19 & 1.8 & $1.0-2.6$ \\
\hline Total & 1,039 & 100 & \\
\hline
\end{tabular}

$\mathrm{Cl}$ : confidence interval for proportions.

The Ethics Committee of the Second University of Naples approved this study (reference number 41/2012).

\section{Results}

\section{Sociodemographic characteristics}

In total, 1,039 parents answered the questionnaire, and $34(3.2 \%)$ refused to participate. Most of the respondents $(89.5 \%)$ were mothers. Compared with the fathers interviewed, more of the mothers were between 20 and 39 years of age $(80.4 \%$ of the mothers vs $59.6 \%$ of the fathers) and fewer were married $(87.2 \%$ of the mothers vs $93.5 \%$ of the fathers). Respondents with more than one child made up $53.1 \%$ of the sample. Only half of the mothers were employed (50.2\% compared with $92.6 \%$ of the fathers) (Table 1 ).

\section{Intention to vaccinate}

Among the 1,039 interviewed parents, 955 (91.9\%) stated that they would certainly $(n=721 ; 69.4 \%)$ or probably $(n=234 ; 22.5 \%)$ vaccinate their children if vaccination were not mandatory. On the other hand, 84 parents $(8.1 \%)$ stated that they would certainly $(n=30$; $2.9 \%)$ or probably not $(n=35 ; 3.4 \%)$ vaccinate their children or that they did not know what they would do $(n=19 ; 1.8 \%)$ (Table 2).

\section{Attitudes and beliefs}

Parents who intended to vaccinate their children if vaccination was not mandatory were generally more favourable toward vaccination and more likely to state that vaccinations are effective, safe (Table 3 ) and rarely or never cause adverse reactions (data not shown). Moreover, they thought that all vaccinations should be mandatory. In the bivariate analysis, all five included attitudinal variables were significantly associated with the main outcome (Table 4)

Knowledge about adverse reactions

Physicians were the main source of information about adverse effects, and intention to vaccinate was 


\section{TABLE 3}

Parents' attitudes and beliefs about vaccinations, Italy, $2013(n=1,039)$

\begin{tabular}{|l|c|c|c|c|c|c|}
\hline & \multicolumn{2}{|c|}{$\begin{array}{c}\text { I am } \\
\text { favourable } \\
\text { toward } \\
\text { vaccination }\end{array}$} & \multicolumn{2}{|c|}{$\begin{array}{c}\text { Vaccinations } \\
\text { are safe }\end{array}$} & \multicolumn{2}{|c|}{$\begin{array}{c}\text { Vaccinations } \\
\text { are effective } \\
\text { in reducing } \\
\text { the risk of } \\
\text { disease }\end{array}$} \\
\cline { 2 - 10 } & $\mathrm{n}$ & $\%$ & $\mathrm{n}$ & $\%$ & $\mathrm{n}$ & $\%$ \\
\hline Agree strongly & 617 & 59.4 & 500 & 48.1 & 729 & 70.2 \\
\hline Agree somewhat & 370 & 35.6 & 466 & 44.9 & 278 & 26.8 \\
\hline I don't know & 12 & 1.1 & 15 & 1.4 & 11 & 1 \\
\hline Disagree somewhat & 32 & 3.1 & 37 & 3.6 & 13 & 1.2 \\
\hline Disagree strongly & 8 & 0.8 & 21 & 2 & 8 & 0.8 \\
\hline Total $^{\text {a }}$ & 1,039 & 100 & 1,039 & 100 & 1,039 & 100 \\
\hline
\end{tabular}

Numbers for each item may not sum to the total study population because of missing values.

positively associated with this source of information. In the bivariate case, parents who had knowledge about potential adverse reactions of vaccines containing mercury or about autism as a consequence of vaccination reported the intention to vaccinate their children less often than those lacking this knowledge. Finally, having a child who had experienced an adverse reaction to vaccination did not affect the intention to vaccinate (Table 4). All data were disaggregated by centre location and by sociodemographic characteristics, but there were no statistically significant associations with the main outcome.

\section{Multivariate analysis}

In the multivariate analysis, the associations between the intention to vaccinate and the three variables on positive attitudes toward vaccinations remained statistically significant. These variables were: being favourable toward vaccination, believing that vaccinations are safe, and believing that vaccinations are effective. The association between not being favourable toward vaccination and knowledge about autism as an adverse effect after vaccination also remained significant (Table 5).

\section{Discussion}

The ongoing debate about obligatory vaccination involves two opposing considerations. On the one hand, the main arguments in favour of obligatory vaccination are that it maintains a high coverage rate. On the other hand, arguments against obligatory vaccination claim that it goes against the principles of selfdetermination and freedom of choice in health matters [18-24]. Moreover, an additional reason for not making vaccines mandatory is that, psychologically, it invites opposition, because individuals object to being told what to do.
TABLE 4

Factors associated with intention to vaccinate, Italy, 2013 $(\mathrm{n}=1039)$

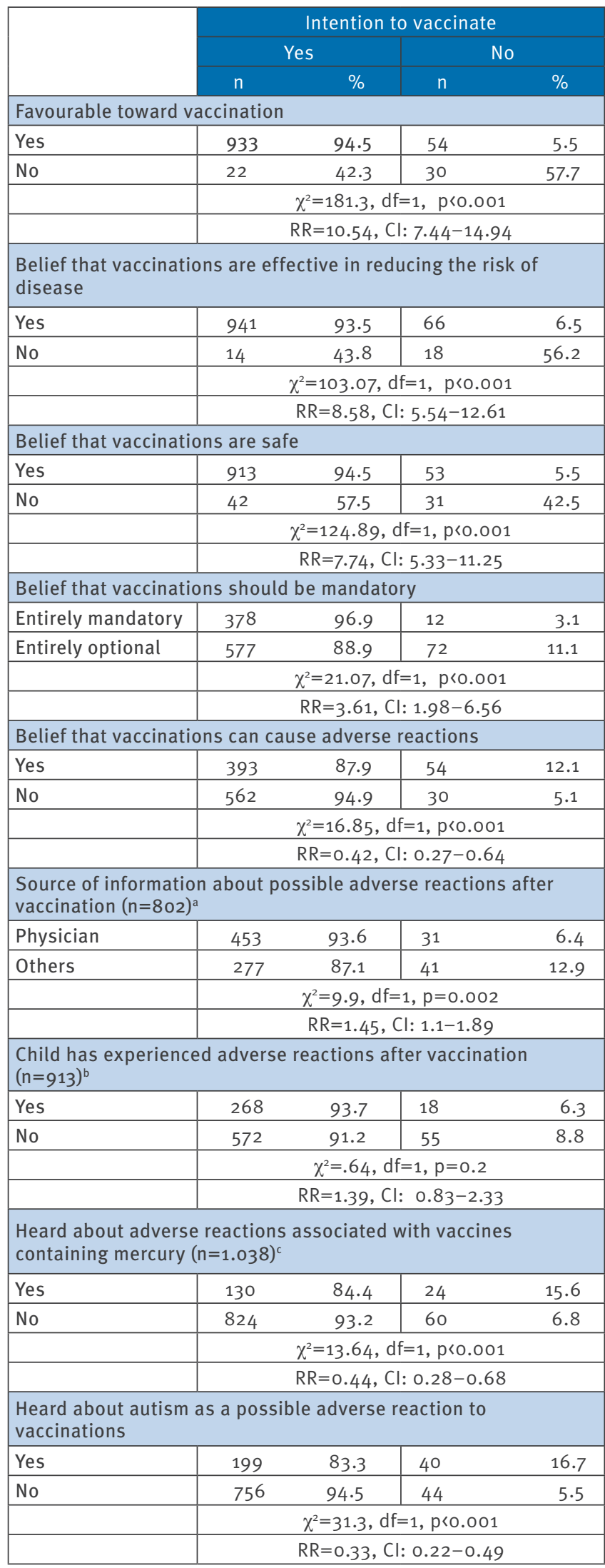

$\mathrm{Cl}: 95 \%$ confidence interval; df: degrees of freedom; RR: relative risk.

A third response option was 'None'.

b A third response option was 'I don't know/I don't remember'. One answer was missing. 
TABLE 5

Multivariate logistic regression analysis predicting the intention to vaccinate children if vaccination was not mandatory, Italy, $2013(\mathrm{n}=1,039)$

\begin{tabular}{|c|c|c|c|c|}
\hline Variable & OR & SE & $95 \% \mathrm{Cl}$ & $\mathrm{p}$ value \\
\hline \multicolumn{5}{|l|}{ Log likelihood: $-149.78, \chi^{2}=123.01(d f=7), p<0.0001$} \\
\hline Favourable toward vaccination & 11.7 & 5.2 & $4.9-27.9$ & $<0.001$ \\
\hline Belief that vaccinations are effective in reducing the risk of disease & $9 \cdot 4$ & $5 \cdot 4$ & $3.04-29.21$ & $<0.001$ \\
\hline Belief that vaccinations are safe & 4.2 & 1.73 & $1.86-9.4$ & 0.001 \\
\hline Heard about autism as a possible adverse reaction to vaccinations & 0.47 & 0.15 & $0.25-0.88$ & 0.02 \\
\hline Belief that vaccinations should be entirely mandatory & 1.97 & 0.79 & $0.9-4 \cdot 3$ & 0.09 \\
\hline Informed about adverse reactions after vaccination by a physician $(n=802)^{a}$ & 0.64 & 0.2 & $0.34-1.2$ & 0.17 \\
\hline Belief that vaccinations can cause adverse reactions & 0.67 & 0.22 & $0.35-1.3$ & 0.24 \\
\hline
\end{tabular}

$\mathrm{Cl}$ : confidence interval; OR: odds ratio; SE: standard error.

a The option "None" has been excluded.

In the past, there was strong concern in Italy that making vaccination non-compulsory would result in lower coverage rates. However, the possibility of an optional vaccination scheme has recently gained popularity. The natural experiment undertaken in the Veneto region beginning in 2008 was both informative and reassuring, as the region's vaccination coverage has remained above the National Prevention and Vaccination Program standard of $95 \%$ after the suspension of obligatory vaccinations (Piano Nazionale Prevenzione Vaccinale 2012-2014) [25]. Based on this experience, the Italian health authorities have frequently declared their intention to make vaccinations non-compulsory nationwide. However, this intention has never been realised because of fear of reducing coverage rates. These fears are driven by the knowledge that the significant sociocultural and economic differences between Italian regions make it impossible to use the experience from one region to make an accurate prediction for others. Indeed, sociodemographic statistics indicate that the population in southern Italy is poorer, less industrialised, has lower employment, and is less educated than northern Italy. These characteristics, known as 'the southern question', exist where this work was carried out, and contribute to the contrast with the Veneto region in northern Italy. In the most recent Italian report on vaccination coverage rates from 2012* [26], the Campania region had the lowest rate (with the exception of the autonomous province of South Tyrol), whereas the Veneto region, even in absence of obligatory vaccination, had a rate that was higher than Campania's and just below the median value for all regions (Table 6).

The present study investigated parents' willingness to vaccinate their children even in the absence of compulsory vaccinations. We found that $91.9 \%$ of the respondents reported that they would certainly or probably vaccinate their children. At first glance, and considering the confidence interval, this result seems quite positive. However, if we consider that $6.3 \%$ of parents stated that they would certainly or probably not vaccinate their children and that the coverage rates in Campania in $\mathbf{2 0 1 2}$ are under the national standard of $95 \%$, it seems likely that the suspension of obligatory vaccination would result in the current coverage rates declining to significantly below $90 \%$. This would represent an unacceptably low level of coverage. These considerations support the caution with which the Italian health authority is addressing this issue.

As expected, and as shown by previous research, the intention to vaccinate is significantly associated with the belief that vaccines are safe and effective [27-31]. However, negative attitudes toward vaccinations were not associated with a significant decrease in the intentions of parents to vaccinate their children. In terms of knowledge about potential adverse effects of vaccination, having heard of autism as a possible side effect after the administration of vaccines was most strongly negatively associated with intention to vaccinate [32]. The effect of this variable is more consistent than the effect of believing that mercury contained in vaccines causes damage [33]. The results were consistent across the four studied cities and for individuals with varying sociodemographic characteristics, potentially providing evidence of homogeneous attitudes toward vaccination throughout the region.

Our results should be interpreted carefully because the willingness to vaccinate children is not the same as the actual behaviour of bringing children for vaccinations. For example, a well-known critical point is that the interviewee may be influenced to respond according to the perceived wishes of the interviewer. Therefore, it is likely that, in the absence of obligatory vaccination, both those who intended to vaccinate their children and those who did not intend to do so might reconsider their positions. Another limitation of the study was the underestimation of the fathers' opinions (i.e. we interviewed only the mothers even when both parents were present). Taking the decision to vaccinate is a complex 
TABLE 6

Vaccination coverage by region, Italy, 2012

\begin{tabular}{|l|c|c|c|c|}
\hline & POL3 & DTP3 & DT-DTP3 & EpB3 \\
\hline Piedmont & 96.5 & 96.5 & 96.6 & 96.3 \\
\hline Valle d'Aosta & 96.3 & 95.7 & 96.4 & 95.9 \\
\hline Lombardy $^{\mid} 96.7$ & 96.5 & 98.8 & 96.5 \\
\hline South Tyrol $^{\text {a }}$ & 89.3 & 89.3 & 89.4 & 88.8 \\
\hline Trento $^{\text {a }}$ & 95.4 & 95.1 & 95.3 & 95.0 \\
\hline Veneto $^{\prime}$ & 94.7 & 94.6 & 94.7 & 94.4 \\
\hline Friuli-Venezia Giulia & 95.3 & 95.1 & 95.5 & 94.7 \\
\hline Liguria & 96.8 & 96.7 & 96.8 & 96.8 \\
\hline Emilia-Romagna & 96.3 & 96.0 & 96.5 & 96.1 \\
\hline Tuscany & 95.3 & 95.1 & 96.6 & 95.2 \\
\hline Umbria & 97.5 & 97.3 & 97.4 & 97.2 \\
\hline Marche & 97.6 & 97.5 & 97.6 & 97.3 \\
\hline Lazio & 98.9 & 98.8 & 98.9 & 99.9 \\
\hline Abruzzo & 99.7 & 99.7 & 99.7 & 99.7 \\
\hline Molise & 97.6 & 97.6 & 97.6 & 97.6 \\
\hline Campania & 93.3 & 93.3 & 94.2 & 93.3 \\
\hline Puglia & 96.5 & 96.5 & 96.5 & 96.5 \\
\hline Basilicata & 99.8 & 99.8 & 99.8 & 99.8 \\
\hline Calabria & 95.8 & 95.8 & 95.8 & 95.8 \\
\hline Sicily & 93.3 & 93.3 & 93.3 & 96.0 \\
\hline Sardinia & & 95.7 & 95.7 & 93.3 \\
\hline
\end{tabular}

Vaccination coverage is expressed in percentages. Numerator: number of subjects vaccinated within 24 months of age with complete cycle (three doses); denominator: number of subjects in the respective birth cohort.

DTP3: diphtheria, tetanus and pertussis (third dose); EpB3: hepatitis B (third dose); POL3: polio (third dose).

a South Tyrol and Trento are autonomous provinces.

Source: Ministero della Salute-Direzione Generale della Programmazione Sanitaria- Ufficio VI [26].

process that presumably involves a discussion between both parents, but this process was too difficult to detect with a short interview. Moreover, the interviews were conducted in a health centre immediately after the administration of the child's vaccination, and this setting probably encouraged a greater amenability to vaccinations. Our population was also older, more urban, more educated, and more likely to be employed than the average regional population because the sample units were the four vaccination centres in the cities with the largest populations in the Campania region. Finally, the sample excluded all parents who did not bring their children for vaccination. These individuals belong to two main groups: parents who have difficulty accessing health services (passive absentee) and parents who decide do not vaccinate their children (active absentee) [11]. Future research should explore the motivations of parents who do not vaccinate their children, especially as the vaccination coverage rates in the Campania region are among the lowest in Italy. Understanding which of these two groups is prevalent in the region (passive or active absentee) is crucial for designing appropriate interventions.

\section{* Authors' correction}

At the request of the authors, the date was corrected from 2011 to 2012 on 5 September 2014.

\section{Conflict of interest}

None declared.

\section{Authors' contributions}

FA: principal investigator, designed the study, wrote the article. CPP: responsible for organization, coordinator of data collection and data entry, contributed to statistical analysis and interpretation. SM and AJVA: data collection and data entry. GS: statistical analysis and interpretation.

\section{References}

1. Haverkate M, D’Ancona F, Giambi C, Johansen K, Lopalco PL, Cozza V, et al. on behalf of the VENICE project gatekeepers and contact points. Mandatory and recommended vaccination in the EU, Iceland and Norway: results of the VENICE 2010 survey on the ways of implementing national vaccination programmes. Euro Surveill. 2012;17(22): pii=20183.

2. Obbligatorietà della vaccinazione antidifterica. [Obligatoriness of diphtheria vaccination]. Legge 6 giugno 1939, n. 891. [Law of 6 Jun 1939, no 891]. Gazzetta Ufficiale della Repubblica Italiana [Official Journal of the Italian Republic]; 1 Jul 1939, n0152. Italian. Available from: http://www.comilva.org/sites/ default/files/R_Legge_6.6.1939_n.891.PDF

3. Obbligatorietà della vaccinazione antipoliomielitica [Obligatoriness of polio vaccination] Legge 4 febbraio 1966, n. 51. [Law of 4 Feb 1966, no 51]. Gazzetta Ufficiale della Repubblica Italiana [Official Journal of the Italian Republic]; 19 Feb 1966, no 44. Italian. Available from: http://www. normattiva.it/uri-res/N2Ls?urn:nir:stato:legge:1966-02-04;51@ originale

4. Obbligatorietà della vaccinazione antitetanica. [Obligatoriness of tetanus vaccination]. Legge 20 marzo 1968, n. 419. [Law of 20 Mar 1968, no 419]. Gazzetta Ufficiale della Repubblica Italiana [Official Journal of the Italian Republic]; 19 Apr 1968 no. 100. Italian. Available from: http://www.normattiva.it/ uri-res/N2Ls?urn:nir:stato:legge:1968-03-20;419

5. Obbligatorieta' della vaccinazione contro l'epatite virale $B$. [Obligatoriness of hepatitis B vaccination]. Legge 27 maggio 1991, n. 165. [Law of 27 May 1991, no 165]. Gazzetta Ufficiale della Repubblica Italiana [Official Journal of the Italian Republic]; 1 Jun 1991, no. 127. Italian. Available from: http://www.normattiva.it/uri-res/ N2Ls?urn:nir:stato:legge:1991-27-05;165!vig

6. Regolamento per l'applicazione del titolo III del decreto del Presidente della Repubblica 11 febbraio 1961, n. 264 , relativo ai servizi di medicina scolastica. [Regulation for the implementation of Title III of the Decree of the President February 11, 1961, n. 264, relating to the services of scholastic medicine. D.P.R. 22 dicembre 1967, n. 1518. [Presidential decree of 22 Dec 1967, no 1518]. Gazzetta Ufficiale della Repubblica Italiana [Official Journal of the Italian Republic]; 6 Jun 1968, no 143. Italian. Available from: http://www.normattiva.it/uri-res/N2Ls?urn:nir:stato:decreto. presidente:1967;1518 art47!vig=

7. Regolamento recante modificazioni al DPR $1518 / 67$ in materia di vaccinazioni obbligatorie. [Regulation containing amendments to Presidential Decree 1518/67 concerning mandatory vaccinations]. D.P.R. 26 gennaio 1999, n. 355 [Presidential decree of 26 Jan 1999, no 355]. Gazzetta Ufficiale della Repubblica Italiana [Official Journal of the Italian Republic]; 15 Oct 1999, no 243]. Italian. Available from: http:// www.edscuola.it/archivio/norme/decreti/dpr51198.html

8. Report sull'attività vaccinale dell'anno 2011: coorte di nascita 2009 e monitoraggio della sospensione dell'obbligo vaccinale. 
[Report on the vaccination activity of the year 2011: birth cohort 2009 and monitoring of the suspension of obligatory vaccination]. Venezia: Regione del Veneto; Jul 2012. Italian. Available from: http://www.pdconsiglioveneto.org/public/ DGR/2012-DGR\%201873_AllegatoA.pdf

9. Prislin R, Dyer JA, Blakely $\mathrm{CH}$, Jonson $\mathrm{Ch}$ D. Immunization status and sociodemographic characteristics: the mediating role of beliefs, attitudes and perceived control. Am J Publ Health. 1998;88(12):1821-6.

http://dx.doi.org/10.2105/AJPH.88.12.1821

10. Benin AL, Wisler-Scher DJ, Colson E, Shapiro ED, Holmboe ES. Qualitative analysis of mother's decision-making about vaccines for infants: the importance of trust. Pediatrics. 2006;117(5):1532-41. http://dx.doi.org/10.1542/peds.2005-1728

11. Samad L, Butler N, Peckham C, Bedford H, Millennium Cohort Study Child Health Group. Incomplete immunisation uptake in infancy: maternal reasons. Vaccine. 2006;24(47-48):6823-9. http://dx.doi.org/10.1016/j.vaccine.2006.06.039

12. Szilagyi PG, Rodewald LE. Missed opportunities for immunizations: a review of the evidence. J Public Health Manag Pract. 1996;2(1):18-25 http://dx.doi.org/10.1097/00124784-199600210-00005

13. Gust DA, Strine E, Maurice E, Smith P, Yusuf H, Wilkinson $M$, et al. Underimmunization among children: effects of vaccine safety concerns on immunization status. Pediatrics. 2004;114(1):e16-22. http://dx.doi.org/10.1542/peds.114.1.e16

14. Salmon DA, Moulton LH, Omer SB, de Hart MP, Stokeley S, Halsey NA. Factors associated with refusal of childhood vaccines among parents school-aged children. Arch Pediatr Adolesc Med. 2005;159(5):470-6. http://dx.doi.org/10.1001/archpedi.159.5.470

15. Guellin BG, Maibach EW, Marcuse EK. Do parents understand immunizations? A national telephone survey. Pediatrics. 2000;106(5):1097-102. http://dx.doi.org/10.1542/peds.106.5.1097

16. Raithatha N, Holland R, Gerrard S, Harvey I. A qualitative investigation of vaccine risk perception amongst parents who immunize their children: a matter of public health concern. J Public Health Med. 2003;25(2):161-4. http://dx.doi.org/10.1093/pubmed/fdgo34

17. Stata Corporation. Stata Reference Manual. Release 10.1. College Station: Stata Press; 2007. Available from: http:// www.stata.com/

18. Walkinshaw E. Mandatory vaccinations: The Canadian picture. CMAJ. 2011;183(16):E1165-6. http://dx.doi.org/10.1503/cmaj.109-3993 http://dx.doi.org/10.1503/cmaj.109-3992

19. Walkinshaw E Mandatory vaccinations: The international landscape CMAJ. 2011;183(16):E1167-8. http://dx.doi.org/10.1503/cmaj.109-3993

20. Walkinshaw E. Mandatory vaccinations: No middle ground. CMAJ. 2011;183(16):1830-1. http://dx.doi.org/10.1503/cmaj.109-3994

21. Sim F, Mackie P. Ethics and equity: choice or compulsion? Public Health. 2012;126(2):85-6. http://dx.doi.org/10.1016/j.puhe.2012.01.001

22. Offit PA. Should childhood vaccination be mandatory? Yes. BMJ. 2012;344:e2434. http://dx.doi.org/10.1136/bmj.e2434

23. Salisbury DM Should childhood vaccination be mandatory? No. BMJ. 2012;344:e2435. http://dx.doi.org/10.1136/bmj.e2435

24. Stefler D, Bhopal R. Lessons to be learnt from other countries about mandatory child vaccination. BMJ. 2012;344:e4036. http://dx.doi.org/10.1136/bmj.e4036

25. Piano nazionale prevenzione vaccinale 2012-2014. [National vaccination programme 2012-2014]. Rome: Ministero della Salute. [Accessed 16 Jan 2014]. Italian. Available from: http:// www.salute.gov.it/imgs/c_17_pubblicazioni_1721_allegato.pdf.

26. Adempimento "mantenimento dell'erogazione dei LEA" attraverso gli indicatori della Griglia Lea. Metodologia e Risultati dell'anno 2012. Roma, Maggio 2014. [Compliance with the supply of LEA through the LEA indicators. Methods and Results of the year 2012]. Rome: Ministero della SaluteDirezione Generale della Programmazione Sanitaria-Ufficio VI; May 2014. Italian. Available from: http://www.salute.gov.it/ imgs/c_17_pubblicazioni_2067_allegato.pdf

27. Gust D, Brown C, Sheedy K, Hibbs B, Weaver D, Nowak G. Immunization attitudes and beliefs among parents: beyond a dichotomous perspective. Am J Health Behav. 2005;29(1):8192.

http://dx.doi.org/10.5993/AJHB.29.1.7
28. Kennedy AM, Brown CJ, Gust DA. Vaccine beliefs of parents who oppose compulsory vaccination. Public Health Rep. 2005;120(3):252-8.

29. Smith PJ, Kennedy AM, Wooten K, Gust DA, Pickering LK. Association between health care providers' influence on parents who have concerns about vaccine safety and vaccination coverage. Pediatrics. 2006;118(5):e1287-92. http://dx.doi.org/10.1542/peds.2006-0923

30. Jones AM, Omer SB, Bednarczyk RA, Halsey NA, Moulton LH, Salmon DA. Parents' source of vaccine information and impact on vaccine attitudes, beliefs, and nonmedical exemptions. Adv Prev Med. 2012;2012:932741. http://dx.doi.org/10.1155/2012/932741

31. Colgrove J, Bayer R. Could it happen here? Vaccine risk controversies and the specter of derailment. Health Aff (Millwood). 2005;24(3):729-39. http://dx.doi.org/10.1377/ hlthaff.24.3.729

32. Stehr-Green P, Tull P, Stellfeld M, Mortenson PB, Simpson D. Autism and thimerosal-containing vaccines: lack of consistent evidence for an association. Am J Prev Med. 2003;25(2):101-6. http://dx.doi.org/10.1016/S0749-3797(03)00113-2

33. Schultz ST. Does thimerosal or other mercury exposure increase the risk for autism? A review of current literature. Acta Neurobiol Exp (Wars). 2010;70(2):187-95. 